\title{
You are a Written Sentence. Cuatro notas sobre literatura y miseria a partir de J. Rancière*
}

You are a Written Sentence. Four Notes on Literature and Misery in Light of J. Rancière

Juan Diego Pérez Moreno

Universidad de los Andes-Colombia

Recibido: 25 de agosto de 2014

Enviado a pares: 28 de agosto de 2014

Aceptado por pares: 22 de octubre de 2014

Aprobado: 10 de noviembre de 2014

Pensamiento y Cultura | ISSN: 0123-0999 | eISSN: 2027-5331

pensam.cult | Vol. 17-2 | Diciembre de 2014 | pp. 73-96

DOI: 10.5294/pecu.2014.17.2.4

- Agradezco a Laura Quintana, profesora del Departamento de Filosofía de la Universidad de los Andes, por sus valiosos comentarios a una versión preliminar de este texto, así como por haberme introducido con su mirada sugerente, iluminadora y crítica al pensamiento de Rancière.

$\diamond$ jd.perezmoreno@gmail.com 


\section{You are a Written Sentence. Cuatro notas sobre literatura y miseria a partir de J. Rancière}

Resumen: Este artículo explora la intimidad que Jacques Rancière propone en algunos de sus textos entre la espectralidad de los cuasi-cuerpos de la literatura y la posibilidad de acoger la existencia suspendida de aquellos cuyas diferencias no-asignables son neutralizadas en un orden consensuado, con la asignación de una identidad miserable. A partir de las posibilidades de pensar esta relación que se anuncia en cuatro fragmentos literarios, se observa cómo el intervalo de desidentificación que se abre en la escritura literaria, aquel en el que la literariedad aparece como la capacidad imprevista de reagenciar las coordenadas de visibilidad e inteligibilidad de un reparto de lo sensible dado, es uno de los topos en los que la subjetivación política puede tener lugar en potencia.

Palabras clave: reparto de lo sensible (partage du sensible), heterología, espectralidad, desidentificación, literariedad (literarité).

\section{You are a Written Sentence. Four Notes on Literature and Misery in Light of J. Rancière}

Abstract: This paper explores the proximity suggested by Jacques Rancière
in some of his texts between the spectrality of literature's quasi-bodies and
the possibility of embracing the suspended existence of those whose non-
assignable differences are neutralized in a consensual order through the
assignation of a miserable identity. Having in mind the possibilities of thinking
such relationship that can be traced in four literary fragments, it shows how
the interval of de-identification that is opened in literary writing, that in which
literariness appears as the capacity of rearranging the coordinates of visibility
and intelligibility that define a given partition of the sensible, can be understood
as one of the sites in which political subjetivation might potentially take place.

Keywords: Partition of the sensible (partage du sensible), heterology, spectrality, de-identification, literariness (literarité). 
It is difficult

to get the news from poems, yet men die miserably everyday for lack of what is found there.

William Carlos Williams, "Asphodel, That Greeny Flower"

¿Puede la literatura acoger la miseria del mundo? De ser así, ¿qué significaría esta acogida? ¿De qué se trata eso que sólo se halla en el poema o que sólo se pone en juego en él, eso que, como nos los anuncian los versos de Williams, podría prevenir la muerte miserable de miles de hombres y mujeres? ¿Cómo entender esta posibilidad de prevención sin someter al poema a una funcionalización de su existencia siempre inútil, aquella que terminaría por neutralizar la potencia desbordante de su inutilidad al imponerle una cierta razón de ser? ¿De qué manera, entonces, podría tejerse una relación entre la letra escrita - entre los fantasmas de sus conjuros- y los cuerpos proliferantes, múltiples y marginados de quienes mueren ahora mismo, mientras escribo estas páginas, en la miseria? ¿Cómo podría la literatura iluminar de un modo insospechado el significado de la miseria para hacer resplandecer en ella aquello que puede escapar de la silueta de su propia sombra? Estas preguntas tiemblan en la sentencia poética que recorre los versos de Williams, sentencia que franquea la frontera entre reinos que parecen inconmensurables - el de la ficción de la palabra escrita y el de lo 'real', el de las noticias, allí donde la miseria acecha con prisa la vida de los cuerpos- por la impropiedad de su planteamiento: la fuerza de las palabras de Williams reside, justamente, en este nexo temible entre la existencia de las voces sin cuerpo de la literatura y aquella de los cuerpos sin voz de los miserables. ¿Cómo pensar este nexo que nos obliga, de entrada, a dislocar el reparto de propiedades de lo literario y de la 'realidad' que suele oponérsele en su definición?

Mi propósito en estas cortas notas es explorar, siguiendo la sentencia de Williams, cuatro escenarios literarios en los que se entrevén cómo las operaciones de la letra escrita podrían aproximarnos a la excentricidad de esta relación; esto sin la pretensión, por supuesto, de llegar así a saturar la inquietud que ella nos plantea. A la luz del horizonte de reflexión que 
se abre en algunos textos de Jacques Rancière sobre "la experiencia de impropiedad y de exilio que liga a la literatura con la inquietud de lo múltiple" $(2012,56)$, observaremos cómo el intervalo (im)propio que se abre en la escritura literaria - el intervalo polémico en el que brota la posibilidad emancipadora de la literariedad (literarité) de un cualquierapuede ser un intervalo potencialmente encaminado a la subjetivación política que perfora y reagencia el reparto de lo común consensual que hace que el miserable sea sólo miserable. Esto nos conducirá a pensar en que si la literatura puede acoger la miseria del mundo es porque esta "acogida pasa muy precisamente por la experiencia de desapropiación de la escritura" (Rancière 2006, 57). Una desapropiación en la que puede iniciarse en la escritura literaria, pero que va ya siempre más allá de ella misma; una desapropiación que, en tanto detonante de cierta desidentificación imprevisible, nos permite no sólo acoger la miseria del mundo, sino hablar con su —nuestro, suyo; he ahí el asunto- rostro múltiple y proteico, nacer con él.

\section{Un grito -la heteronomía del yo literario}

¿De qué se trata este ahí (there)? ¿En qué sentido se configura en el poema o, si se quiere, en el espacio de la escritura literaria - si es que podemos asignar un espacio a lo que este ahí demarca- algo de lo que carecen quienes mueren miserablemente, algo de lo que carece el mundo que los llama miserables, algo que se encuentra particularmente ahí (what is found there), en ese espacio escritural? Podemos aventurar una respuesta a partir de otro verso, el último del poema "Un hombre pasa con un pan al hombro" de César Vallejo: “¿Cómo hablar del no-yo sin dar un grito?” $(2008,39)$. Esta pregunta de la voz poética queda suspendida en los límites de sí misma, en los límites de una escritura que pretende volcarse hacia afuera de las fronteras del yo que habla. Un yo que, así, encuentra aquí sus extramuros en un no-yo que excede y fractura el régimen del habla articulada que le pertenece y que, paradójicamente, es también la que lo enuncia: un no-yo cuya enunciación disloca cierta palabra inteligible (logos) asociada a la propiedad del yo sobre sí mismo al hacerla operar al servicio de su opuesto —el ruido que es expresividad ininteligible (phoné), insensatez sonora: el grito. 
En tanto que este verso nos habla del no-yo haciendo uso de la palabra reguladora del régimen de propiedad del yo, su gesto de apertura y suspensión interrogativa interrumpe esta pretendida auto-apropiación del yo en una escritura que reafirme su autonomía al introducir lo impropio (el no-yo, el grito) en el reino de la propiedad o, lo que es lo mismo, al desajustar la frontera entre el logos del yo y la phoné del no-yo. El espacio que se abre en este verso es, pues, el espacio de la escritura literaria, como si lo 'propio' de ella, de su ser literatura, fuera abrir esta impropiedad en la que un yo, un habla articulada, regulada y reguladora de un régimen de sentido o un sensorium establecido, se expone a un grito impropio que la desafía con un quiebre subrepticio, que la divide y la multiplica en y como él. Se trata, diríamos, del espacio de lo propio como impropio puesto que, en palabras de Rancière, "lo que desaparece [en él] es la operación propia del texto: no la conquista de sí, sino la conquista de la posición del yo que escribe, la introducción de un él en la relación de yo a yo" $(2010,53)$. La introducción de un no-yo que abre un espacio suspensivo de (im)propiedad en el que la escritura se pertenece sólo a sí misma en su resistencia, esto es, en el movimiento de desapropiación heterónoma en el que se sumerge todo yo que en ella habla - habla $y$ grita.

Esta introducción de la heteronomía en la configuración del yo que tiene lugar en ese ahí suspendido o (im)propio de la escritura (heteronomía que podría comprenderse incluso como una suerte de opacidad del sujeto que busca afirmar su autonomía transparente en el yo escrito, pero que falla en su pretensión de buscar el retorno regulado a sí de tal auto-transparencia), tiene dos efectos que iluminan su relación con la miseria que se anuncia en los versos de Williams. En primer lugar, la aparición de este él que no permite que se cierre un círculo de auto-identificación entre el yo que escribe y el yo escrito, supone la ruptura de un nexo necesario entre la expresión y su contenido o, dicho de otro modo, entre la palabra escrita y un determinado régimen de inteligibilidad que regule su modo de significación y, con él, su modo de visibilización de cierto reparto de la vida social. Este intervalo de (im)propiedad que se abre en versos como el de Vallejo 
interrumpe, podríamos decir con Rancière, la lógica policial ${ }^{1}$ que asigna palabras a discursos autorizados, trazando así unos espacios de identificación en los que unos se pertenecen a otros a la luz del reparto de propiedades que ejerce un logos regulador.

Al abrir el intervalo de cierta heteronomía en el yo, el grito de la escritura literaria hace visible las singularidades espectrales de unas voces inapropiadas e inapropiables, voces sin cuerpo fijo o siquiera fijable y, de ese modo, puede inscribir en ella la existencia de unos seres sin cuerpo o, si se quiere, de unos cuerpos fantasmales. En este sentido, este dispositivo de la heteronomía del yo literario introduce un movimiento de desidentificación en la medida en que "la literatura es el reino de la escritura, de la palabra que circula por fuera de toda determinada relación de discurso. [...] La escritura significa lo inverso de todo lo propio del lenguaje: significa el dominio de la impropiedad" (Rancière 2011a, 28-29), dominio cuyo espacio intersticial y por ende no-asignable -el ahí del poema, del yo literario- inscribe en el reparto de una palabra reguladora la existencia suspensiva de aquellos que exceden la cuenta dada de modos de decir, que dicho logos configura, autoriza y distribuye: aquellos cuyas voces aparecen sólo como phoné en el reparto autorizado de inteligibilidad en tanto que no coinciden con ninguna de las identidades dadas entre palabras y discursos propios. El grito de la letra escrita es así el grito - aunque nunca sólo esto, pues tal reducción o

1 La policía es uno de los conceptos centrales que Rancière introduce en su análisis del ordenamiento de la vida social de una comunidad - esto es, de la distribución de las funciones, los lugares, los títulos y, en general, las capacidades apropiadas de los sujetos que tal distribución pone en marcha como las propiedades necesarias que definen los límites de lo posible en dicha comunidad. La policía no debe entenderse, según advierte de Rancière, solamente en el sentido de las lógicas de represión que garantizan el control social (cf. 2011b, 164), dado que se trata, en su base, del proceso de ordenamiento en el que cada cuerpo es incorporado gracias a una función, un lugar, un título y unas capacidades que le son asignadas arbitrariamente para definir su propiedad como sujeto. De ahí que la policía sea la actividad que "consiste en acomodar a los hombres en comunidad y consentimiento, y descansa en distribución jerárquica de lugares y funciones" (2006, 17, énfasis mío) que se legitiman, en consecuencia, gracias al presunto consenso que da forma a los límites de una comunidad o, ya podemos decir, a los límites de un reparto de lo común dado. En los cimientos de la lógica policial hay, por lo tanto, el presupuesto de una ley consensual de desigualdad entre los sujetos que ella misma produce en la regulación, la afirmación y la distribución jerárquica de sus modos de ser apropiados. 
asignación definitiva de sentido es siempre imposible- de la existencia no-asignable de aquellos que los órdenes consensuales pretenden erradicar del mundo visible al fijar un régimen de visibilidad como inteligibilidad y viceversa; aquel que los mira al nombrarlos articuladamente, por ejemplo, como miserables. Al desvirtuar la correspondencia entre la intención de quien escribe y el significado de la palabra escrita, al interrumpir la pretendida transparencia de su reflejo, la literatura abre de esta manera un espacio para que resuene la voz impropia e inapropiable de quienes no podían hablar: aquellos cuya excedencia y multiplicidad se regula a través de su marginalización - su invisibilización, su enmudecimiento- en el cuerpo regulado, inteligible y asignable de la miseria.

En segundo lugar, esta dislocación de los nexos entre la voluntad del yo que escribe, el significado de la palabra escrita y su posible destinatario interrumpe las asignaciones entre los cuerpos, los discursos y las capacidades de los sujetos cuyas identidades contadas operan en un determinado reparto de lo común. La interrupción del régimen policial de identificación que tiene lugar en el ahí de la literatura termina por abrir, en efecto, el intervalo en el que puede hacerse visible, "por sobreimpresión en la cuenta de las partes de la comunidad y la completitud de los cuerpos, [...] la existencia de seres sin cuerpo, de seres hechos de palabras que no coinciden con ningún cuerpo" (Rancière 2010, 53, énfasis mío). Tal como sucede con el yo heterónomo que se despliega en el verso de Vallejo, la introducción de un él en la relación del yo consigo mismo que menciona Rancière implica su desidentificación de un cuerpo propio cuyos modos de decir, de hacer y de ser los regula el logos que ordena la cuenta dada de una comunidad orgánica, articulada, consensual.

De ahí que la experiencia de (im)propiedad, de exilio o de inhabitar (cf. Rancière 2010,52) que se erige en y con la escritura literaria abra la posibilidad una ruptura o interrupción desincorporadora, "una ruptura simbólica de un orden determinado de relaciones entre los cuerpos y las palabras, entre las maneras de hablar, las maneras de hacer y las maneras de ser" (Rancière 2011a, 27) en la que, por ende, se desvirtúa el pretendido carácter necesario de la posición marginal —esto es, visible como invisible- del miserable, aquel cuyo cuerpo y discurso no tiene parte en 
el reparto de la cuenta dada. La trascuenta que evidencia la identidad no-asignable perfora así, a través de las palabras sin cuerpo que emergen en este intervalo desincorporador, el consenso de la comunidad cuyo logos policial establece el orden de identidades 'propias' que hace que el miserable sea sólo miserable. Pero no solo ello, pues en el espacio de esta perforación, de este grito, dicha trascuenta pone de manifiesto que cualquier yo -cualquiera, incluso aquel que se piensa auto-transparente en su conformidad con las identificaciones del consenso- está ya atravesado por la espectralidad del inhabitar de las existencias suspensivas que su mirada busca regular, incluso, en sí mismo. El poder del ahí de los enunciados literarios frente a la miseria del mundo reside, pues, en la posibilidad que la escritura tiene para dar voz a unos "cuasi-cuerpos, bloques de palabras que circulan sin padre legítimo que las acompañe a un destinatario autorizado" (Rancière 2006, 50): cuerpos (im)propios cuya resistencia a la incorporación visibiliza la singularidad excesiva $y$ múltiple del marginado, el cualquiera, el 'uno-de-más'. La singularidad ruidosa, 'marginal' y 'miserable', diríamos, que nace con los espectros la heteronomía constitutiva de cualquiera que se diga - cualquiera que predique de otro, como predica de sí mismo-yo.

\section{El pez magnífico, o la(s) existencia(s) suspendida(s)}

¿En qué sentido podrían los cuasi-cuerpos de la escritura literaria abrir un horizonte en el que el miserable no sea sólo miserable? ¿Cómo podría aquello que sólo se halla en el poema interrumpir la lógica que, como nos sugieren los versos de Williams, hace que los hombres mueran miserablemente? Detengámonos ahora en la letra escrita, la letra proliferante y fugitiva, en la que resuena la voz de un cuasi-cuerpo literario. El mundo de Hant'a, el entrañable narrador-protagonista del relato Una soledad demasiado ruidosa de Bohumil Hrabal, parece estéril, desolador y claustrofóbico a primera vista: su vida transcurre en un sótano de la Praga estalinista en el que, desde hace más de 35 años, su trabajo consiste en triturar papel prensado de libros y reproducciones de obras de arte. Hant'a es un obrero cuyo repertorio de capacidades parecería 
agotarse en las paredes de su cárcel subterránea y en los movimientos maquínicos de sus brazos. Sin embargo, el discurso en primera persona de este personaje que se narra a sí mismo en una suerte de soliloquio introspectivo, configura un cuasi-cuerpo no contado, una singularidad excesiva cuyas palabras reagencian un espacio que, en el reparto policial del orden soviético, hace invisibles a ciertas subjetividades al marginalizarlas con la demarcación de una geografía de la miseria. Como sus palabras, las manos de Hant'a dislocan esta geografía puesto que suspenden los procesos de identificación al horadar, con sus trazos singulares e imprevistos, el reparto de modos de ser, decir y hacer del orden policial: "Pero, al igual que en las aguas sucias y turbias de un río en el desagüe de una fábrica resplandece de vez en cuando un pez magnífico, en el río de papel viejo resplandece a veces un libro precioso. Mi ritual consiste no sólo en leer estos libros, sino en meter alguno en cada paquete que preparo, y es que tengo la necesidad de embellecer cada paquete, de darle mi carácter, mi firma" (Hrabal 2009, 27-28, énfasis mío). En las manos/palabras de este cuasi-cuerpo literario, los desechos miserables son tesoros en los que resplandece el carácter de un tránsfuga, un 'pez magnífico'?

La capacidad de reconocer el resplandor de la letra escrita en medio de un río de papel viejo y, más allá, de encontrar en su mutismo la oportunidad de embellecerlo - esto es, de ubicarlo en otro paisaje estético a

2 Rancière se refiere con este nombre a la singularidad excesiva y múltiple del 'uno-de-más', aquel que escapa o se fuga de las líneas con las que el orden policial reparte las propiedades y capacidades entre los cuerpos que así se identifican para su incorporación. Los tránsfugas, los sujetos híbridos que siguen el movimiento heterónomo de la letra escrita y su palabra suspensiva, es decir singularidades cuya (im)propiedad los ubica en un entre que no puede clasificarse, interrumpen la lógica de la adecuación y de asignación 'apropiada' que determina los límites de la cuenta de un cuerpo social consensual. Como dice Rancière, "entre la promesa del cuerpo popular a disposición y el acto de escritura que debe hacer coincidir un yo consigo mismo, está este 'ser de fuga"' $(2006,55)$, este ser excéntrico cuya excedencia pone en cuestión el reparto (partage) de lo común al que se resiste el cruce polémico de lo visible y lo invisible en su identidad imposible, este ser de y en fuga que 'no tiene parte' allí. La noción de tránsfuga se remonta al análisis de la superposición impropia del orden social obrero y del burgués que Rancière explora en los testimonios de proletarios como Gauny o Pérdiguier en La noche de los proletarios (1981). El transfuguismo es una noción clave a la hora de entender cómo en el proceso de desidentificación del miserable se configura y hace visible el horizonte del démos proletario, al que llegaremos en la cuarta nota de este texto. 
través de la dislocación de un reparto de lo sensible dado- ${ }^{3}$, descubre en Hant'a capacidades mutiladas por la cuenta policial que ponen de manifiesto, como diría Rancière, que en su relato estamos ante una subjetividad cuya singularidad se forja en el movimiento suspensivo de "una identificación imposible, una identificación que no puede encarnarse en aquellos o aquellas que la enuncian" (2006, 22). La experiencia escrita de Hant'a, experiencia que no en vano tiene lugar en el ahí (im) propio de la escritura literaria, hace visible "el intervalo o la falla entre dos identidades" (Rancière 2006, 22): la del obrero a la sombra de la prensadora y la del lector, artista y narrador que firma los paquetes y rescata obras desechadas al espacio de la miseria, obras preciosas que los ojos de Hant’a, que son también los del obrero, saben ver. El cuasicuerpo de este personaje intersticial habita -o, para ser precisos, habita deshabitando, (des)habita - de esta manera, un intervalo de desidentificación que se abre aquí con la literatura, tanto en el texto de Hrabal como en la escritura de las acciones-palabras singulares del personaje: el entre de la ubicación (im)posible e (im)propia de una identidad que desborda las fronteras del reparto de lo común consensuado por el orden policial, esto es, el entre de una(s) singularidad(es) no-identificable(s) que "está entre el nosotros enunciador y el nombre del sujeto enunciado, entre un sujeto y un predicado, entre cuerpos y significaciones"

3 El reparto de lo sensible (le partage du sensible) es uno de los conceptos transversales de la obra de Rancière que resulta fundamental para comprender cómo en la configuración de regímenes estéticos de visibilidad está implicada la repartición y asignación de propiedades con las que se definen las fronteras de inclusión y exclusión de un determinado común consensuado. "Llamo reparto de lo sensible", escribe Rancière, "a ese sistema de evidencias sensibles que al mismo tiempo hace visible la existencia de un común y los recortes que allí definen los lugares y las partes respectivas" $(2009,9)$, es decir los trazos que dan forma a la correspondencia policial entre modos de decir, hacer y de ser en los que se define quién puede tener una parte activa en el reparto de lo común. El reparto de lo sensible se vincula así con la formación de un cierto régimen de percepción estética — de visibilidad y de la inteligibilidad a ella asociada- en el que aquel cuya singularidad no conviene a esas coordenadas afectivas ocupa la posición del excluido de la comunidad política, aquel que encarna el exceso que se identifica e incorpora en el orden policial bajo el rótulo del Otro miserable. Aquel que, sin embargo, es ya siempre también un cualquiera cuya existencia suspensiva en el régimen de identificación del reparto dado y, desde su posición polémica e incontrolable, revindica su poder de reagenciar la lógica de los afectos consensual y sus rótulos identificadores — por encima de todos y de entrada, aquella que lo nombra, justamente, como miserable. 
(Rancière 2011b, 162). El discurso excesivo y remanente de Hant'a, la voz 'miserable' de su soledad demasiado ruidosa, consigue así desvirtuar la frontera entre la palabra autorizada (logos) y el ruido de lo marginal (phoné) que da forma a la geografía de la miseria. Los enunciados de este obrero "introducen en los cuerpos colectivos imaginarios líneas de fractura” (Rancière 2009, 50) en las que la asignación 'necesaria' entre sujetos y predicados se suspende: en el pliegue del entre la miseria no es sólo miseria, sino la abertura de un espacio heterotópico que (des) habitan seres que, como la letra escrita, horadan el consenso comunal con su existencia suspendida.

El entre (im)propio que abre la escritura literaria se anuda entonces con la 'inquietud de lo múltiple' que menciona Rancière y que resuena en la advertencia de los versos de Williams (yet men die miserably every day...) dado que, como dice el primero, "el modo de ser de la literatura es el modo suspensivo de la palabra. Llamo suspensiva a una existencia que no tiene lugar en una repartición de las propiedades y los cuerpos" $(2006,51)$, una existencia que no permite, por consiguiente, su reificación en una esencia fija y funcional; una existencia liminal, sin más, que no obedece al orden de la identificación policial, puesto que su movimiento intersticial se resiste a los procesos de incorporación cuya operación parece estar fundamentada en la asignación transparente de sentidos de un régimen representativo ${ }^{4}$. La miseria es sólo miseria, solo

4 La liberación de la letra escrita de la voluntad de significado del hablante, esto es, la interrupción de la correspondencia arbitraria entre escritura y habla que se deriva de la heteronomía de los cuasi-cuerpos literarios, se enmarca en lo que Rancière llama el paso de régimen representativo clásico al régimen estético del arte, paso en el que no puedo detenerme aquí con el cuidado que merecería. Baste decir que el primero, que se deriva de la división aristotélica entre la necesidad de lo poético y la contingencia de lo histórico, implicaba la operación de la representación necesaria entre significantes y significados que "enlazaba la racionalidad de la ficción poética a una cierta forma de inteligibilidad de las acciones humanas, a un cierto tipo de adecuación entre maneras de ser, de hacer y de hablar" (Rancière 2011a, 24-25). En el régimen representativo se establecía así una cuenta definida o un reparto limitado de las conveniencias entre sujetos y predicados, cuerpos y significaciones, que en última instancia instauraban una división arbitraria entre quienes podían hablar 'propiamente' y quienes no $-\mathrm{o}$, si se quiere, entre un logos regulador y una phoné que debía permanecer en silencio. Si bien este régimen predomina en la comprensión clásica del arte, instituye una forma de inteligibilidad para Rancière que, hasta cierto punto, sigue operando algunas comprensiones del arte moderno y contemporáneo. El surgimiento de la práctica de escritura que se llamaría 
marginalidad ruidosa, en el marco del reparto de lo común que se deriva de tal operación. Como señala Rancière, en la base del orden policial se erige una ontología del salvaje o una ley sobre el no-ser que purga y expulsa la existencia suspensiva de los 'uno-de-más', de aquellos otros cuya singularidad siempre plural y no-asignable desajusta la cuenta dada de la comunidad consensual, unificando sus propiedades disjuntas en "la categoría específica de lo múltiple como categoría del Otro que no puede ser acogido" $(2006,47)$ : el otro marginalizado y silenciado en este proceso de identificación representativa, el otro miserable.

Aquello que se encuentra en el poema, aquello que Hant'a descubre en sus rituales literarios, es que la circulación imprevisible de la letra escrita anuncia que las asignaciones apropiadas, adecuadas y convenientes entre sujetos y predicados que se trazan a partir esta suerte de ontología de la exclusión, son siempre arbitrarias y que, por lo tanto, pueden reagenciarse en y desde el ahí que resalta Williams: el entre excesivo de la literatura en el que proliferan los cuasi-cuerpos de las singularidades múltiples que dicha ontología pretende eliminar con la violencia de su operador universal. Es por esto que "el intervalo político tiene que ver más con el salto de la metáfora que con toda forma de comunión" (Rancière 2011b, 162): la política ${ }^{5}$ aflora en el pliegue metafórico e

literatura desde el siglo XIX —entre otras prácticas de sentido, por supuesto- perfora esta lógica de la asignación en tanto que la libertad proliferante de la letra escrita, su potencia infinita de significación y circulación aleatoria, inaugura una "nueva manera de ligar lo decible y lo visible, las palabras y las cosas" (Rancière 2011a, 24) que rompe con este sistema de adecuación y regulación al revelar su arbitrariedad y, con ella, la posibilidad de reagenciar poéticamente - estéticamente, en un campo expandido- el reparto dado de lo sensible y lo común - vale decir, de lo 'real'. La relación entre literatura y proletariado se anuda, precisamente, en la reproducción excesiva y sin ley de significados y de múltiples singularidades banales, respectivamente. Para retomar a Williams, diremos que solo en un mundo gobernado por la lógica representativa será difícil conocer a través del poema los sucesos 'reales' (the news) que en él acontecen: sucesos que siempre podemos aprender a ver siguiendo lo que en el ahí (there) del poema mismo puede hablarnos (im)propiamente.

5 La política es uno de los conceptos transversales del pensamiento de Rancière cuyo sentido se modula de diferentes maneras a lo largo de su obra, razón por la que tratar de definirlo exigiría un trabajo de exégesis que excede los límites de este artículo. Para efectos de la intimidad que aquí nos ocupa entre la impropiedad de la escritura literaria y el topos de una posible desidentificación, baste recordar que "la política no es la dominación ni la gestión, sino que define una actividad excedentaria precisamente respecto a la lógica de la dominación y 
insaturable entre sujetos y predicados que la existencia suspendida de la letra escrita hace visible, allí donde la soledad de Hant'a puede reescribir el mundo con los trazos (im)propios de una voz y su soledad demasiado ruidosa - su voz que, aunque solitaria a veces, se resiste en cada una de sus palabras a ser sólo ruido.

\section{La igualdad de los hablantes (manos para ver)}

Ahora bien, ¿en qué medida podría ser el pliegue no-asignable de la letra escrita un pliegue político también? ¿Por qué decir que este entre de la trascuenta, este vértice de la fuga en el que la(s) singularidad(es) múltiple(s) de los tránsfugas reescriben el reparto de lo común con sus cuasi-cuerpos proliferantes, es un intervalo político? ¿Qué relación tiene la política con esta falla idiomática o este "no-lugar lógico" en el que se anuncia el vértice (im)propio de la desidentificación, "el lugar de una demostración polémica" (Rancière 2006, 20)? Si el intervalo que emerge en el espacio literario puede pensarse como el topos de tal demostración polémica, es porque su perforación del régimen de sentido en el que se sostiene un determinado reparto policial de lo común construye escenarios imprevisibles de enunciación en los que podría hacerse visible - podría demostrarse - un reclamo ante otros. De ahí que, aunque por sí mismos no sean ya escenarios políticos (no se trata aquí de otorgarle una función utópica o redentora a la literatura), los intervalos metafóricos que la escritura literaria hace visible cuenten con una potencia política en tanto que su (im)propiedad abre el espacio polémico, justamente, para la

de la gestión" (Rancière 2011b, 76). Esta actividad excedentaria, esta actividad de un cierto exceso incontable o trascuenta sobre la cuenta del trazado dominante y su gestión ordenadora, pone de manifiesto que las propiedades necesarias que la actividad de la policía asigna y reproduce en su reparto de lo común son siempre contingentes y, por lo tanto, siempre susceptibles de ser fisuradas, redistribuidas, re-agenciadas. Es por esto que, como afirma Rancière, "no hay política si no se franquean los límites que el orden que llamo policial determina como los límites de los posible" (2011b, 77): los límites de un cierto régimen de visibilidad e inteligibilidad de una comunidad consensual que la política disloca. Así pues, la actividad excedentaria de la política consiste en el juego de prácticas guiadas por la presuposición y la verificación de una igualdad de cualquiera con cualquiera (Rancière 2006, 17): una igualdad disensual e impropia, si se quiere, que se opone y confronta la presunción de la ley consensual de desigualdad a partir de la cual el régimen policial produce la propiedad de sus sujetos - de su cuenta, su lugar y su función. 
potencial escenificación, visibilización o demostración de un daño ocasionado por la repartición policial de los modos de decir, hacer y ser que dan forma a una comunidad de sentidos consensuados. Una demostración, al mismo tiempo, de la capacidad de hablar — esto es, de configurar sentidos polémicos- que un cualquiera pueden reclamar para sí.

La apertura de este topos - topos de un daño, pero también y sobre todo, de su posible demostración polémica en el reclamo-, como se nos susurra entrelíneas en los siguientes versos del poema "La cortesía de los ciegos" de Wislawa Szymborska, tiene que ver con el señalamiento de las fronteras excluyentes que hacen que el Otro - el uno-de-más, el outcast, aquel cuyo horizonte de visión excede el régimen de visibilidad regulado por el orden policial- sea sólo un otro ciego - otro invidente e invisible, mudo, marginal y, en breve, miserable: "Alguno de ellos incluso se acerca / con un libro abierto al revés / pidiendo un autógrafo invisible para él" $(2007,51)$. Aquí el ciego es una figura que desborda los límites de una discapacidad física identificable: la voz poética se resiste a nombrarlo como tal y, a cambio, conjura el cuasi-cuerpo literario de un alguno anónimo. El reclamo que subyace en su gesto - la petición de un autógrafo o de una firma, tal vez, como la de las manos de Hant'a, esto es, de la verificación escrita de una singularidad cuya existencia emerge en su suspensión en y como letra- se hace entonces en nombre de todo aquel que está condenado a la ceguera: todo aquel cuyo modo de ver no coincide con las líneas del reparto de lo sensible dado, cuya parte en el común consensuado es la del que no puede ni quiere tener parte. Sin más, todo alguno cuya alteridad incontada señala un daño compartido con los otros que (des)habitan un entre prohibido, ya que "el nombre de una categoría víctima de un daño [...] es siempre el nombre del anónimo, el nombre de cualquiera" (Rancière 2006, 19). El nombre, entonces, de aquellos que se hacen ver como la parte de una comunidad consensual que no tiene parte en ella y que, más allá, se rehúsa a ser asignada como tal: se rehúsa a ser pensada como una parte más del reparto que la excluye o, lo que es lo mismo, reclama para sí la capacidad de leer el mundo con -y no sólo con, sino más allá de... - sus ojos ciegos.

El carácter político del intervalo literario en el que estos tránsfugas anónimos pueden reagenciar la repartición policial de cuerpos y propie- 
dades se evidencia en el tránsito hacia esta identidad o, mejor, esta posición identitaria (im)propia de los cualquiera, es decir de quienes son víctimas no en virtud de la herida de una esencia compartida cuyo reconocimiento e inclusión se reclama sino, más bien, de quienes sufren en su multiplicidad singular el daño que impone la fractura de la marginalización que los encierra en la miseria. La política aquí no tiene tanto que ver, pues, con la reivindicación de unos derechos particulares de una clase miserable específica como con la apertura del espacio polémico de visibilización del daño que sufre la singularidad excesiva y no-asignable de los fuera-de-cuenta en el mundo social consensuado alrededor de dicha fractura; de ahí que, en palabras de Rancière, el entre de la escritura literaria sea un no-lugar político o, si se quiere, un espacio heterológico cuyo disenso perfora el común consensual al hacer visible "la homonimia del proletario, que más refiere al nombre de un múltiple singular que al de una categoría social" $(2006,49)$, el nombre de una pluralidad de existencias singulares que, incluso, deshace la posibilidad de configurar categoría social.

El reclamo del ciego como proletario, como aquel cuya visión (recordemos los ojos de Hant'a) sobrepasa la distinción desigual del orden policial entre quien puede ver y quien no, es entonces un reclamo político en la medida en que el daño que evidencia parte de "la presuposición de la igualdad de cualquiera con cualquiera" (Rancière 2006, 18) y, para ser precisos, de la preocupación por verificar "la igualdad de cualquier hablante con cualquier otro" (Rancière 2006, 19): una igualdad que se confirma justamente en el pliegue (im)propio de la literatura en el que la voz de alguno, de su cuasi-cuerpo sin nombre, puede hablar. Esta verificación supone hacer ver la igualdad en la desigualdad, tal y como el gesto del ciego hace ver su capacidad de leer en su ceguera, en tanto que señala el daño en la fractura de la lógica de la desigualdad del orden policial, esto es, en la apertura de un topos de enunciación - de reclamo, de demostración polémica - en el que se verifica la igualdad de cualquiera con cualquiera como hablantes, como sujetos que se nombran a sí mismos (y así nombran también un mundo múltiple singular, un reparto otro) como la parte incontada, siempre incontable, de aquellos cuya voz no corresponde a su cuerpo 'miserable'. Así pues, el intervalo literario es un intervalo potencialmente político o, mejor, el intervalo de 
una posible - pero jamás necesaria, pues cualquier lógica que pretenda garantizar este paso necesario es, justamente, la que se pone en cuestión aquí- desidentificación política, porque pone de manifiesto un lugar de enunciación excéntrico y múltiple que invalida la frontera imaginaria entre logos y phoné al señalar la desigualdad inherente al reparto sensible $y$ político de cierto común consensuado, esto es, del cuerpo social delimitado por la lógica de la cuenta dada. Al reclamar su lugar como hablante agente $-\mathrm{o}$, siguiendo la metáfora del poema, como ciego vidente- el gesto del alguno verifica con su desplazamiento de los trazos policiales que "la igualdad tiene efecto en el cuerpo social bajo la forma de existencias suspensivas, que pueden llamarse literatura o proletariado" (Rancière 2006, 54), sentidos y cuerpos proteicos e imprevisibles ${ }^{6}$.

Corriendo el riesgo del reduccionismo al que la literatura y el proletariado - uno y otro, aunque nunca uno necesariamente como el otro- se resisten, este efecto podría describirse como el de la explosión de las reglas de inclusión y los modos de visibilidad del sistema de 'conveniencias' policiales que se corresponde con la explosión de la literariedad (literarité) de un sujeto potencialmente desidentificado (potencialmente político, vale decir, si tal desidentificación desembocara en la verificación de un daño)

$6 \quad$ La relación entre la letra escrita y la verificación de la igualdad en la que se hace visible "la parte de los sin parte" o, si se quiere, la posición de enunciación igualitaria en la que el proletario puede ser un hablante, se deriva para Rancière de los efectos políticos que se anuncian con el surgimiento de la literatura en el siglo XIX. En la 'petrificación literaria' que se despliega en las obras de Balzac, de Hugo y particularmente de Flaubert, obras en cuyos matices y diferencias no puedo detenerme aquí, Rancière descubre que "la absolutización del estilo era la fórmula literaria del principio democrático de la igualdad" (2011a, 26), igualdad que puede señalarse para él en tres niveles en los que se suspende o interrumpe la lógica de la adecuación que gobierna al régimen representativo clásico (cf. Rancière 2011a, 48). Primero, la igualdad de los temas que hace que toda palabra esté disponible para construir el tejido de la vida de cualquiera; segundo, la igualdad entre las cosas mudas y el discurso de los oradores autorizados por un logos regulador; y tercero, la igualdad molecular que permite escuchar singularidades que exceden la lógica molar de los sujetos identificables. Valdría la pena detenerse en otro lugar en cómo en este principio democrático que opera en la literatura, puede rastrearse la transformación de la identidad del miserable, el Otro cuya phoné se opone al logos que gobierna el reparto de lo común dado, en la identidad fugitiva e (im)posible del proletario, el fuera-de-cuenta cuyo cuasi-cuerpo es una singularidad múltiple que se resiste a su incorporación policial: un miserable que, parafraseando a Hugo, deja de ser un demonio para resistir como un espectro (ctd. Rancière 2006, 58). 
que se forja en el no-lugar indomable del 'salto de la metáfora'. En las manos del alguno de los versos de Szymborska hay un libro abierto al revés que, sin embargo, jamás está al revés para quien lo porta sino solo para la voz poética que, al detenerse en este quiebre perceptivo, anuncia al escenario de la desigualdad — que, por demás, no en vano es un libro- como aquel en el que emerge un régimen de visibilidad imprevisto que verifica cierta igualdad, cierta capacidad de leer. El autógrafo es ciertamente "invisible para él”, para el outcast, no porque él no pueda ver la singularidad que allí se verifica, sino porque su gesto reagencia el reparto entre lo visible y lo invisible, entre lo decible y lo enmudecido, que lo identifica como ciego miserable y así, introduce un trazado sensible nuevo en el que lo invisible también puede ser visto - o, si se quiere, en el que sus manos pueden leer las letras (in)visibles de una escritura (im)propia.

Es en esta capacidad poética o literaria del proletario de desplazar las relaciones entre cuerpos y denominaciones, sujetos y predicados o significados y significantes, es decir en esta capacidad de reescribir el reparto de lo sensible que lo invisibiliza y los modos de inteligibilidad (o de legibilidad) que de él se derivan, que se vislumbra — sin garantía alguna de su cumplimiento, sin ningún horizonte utópico que lo confirme...- la posibilidad de su subjetivación heterónoma en un reparto de lo común nuevo, un reparto heterológico que subvierta de la lógica de la adecuación del orden policial. "El hombre es un animal político porque es un animal literario" (Rancière 2009, 50) en tanto que su capacidad para dislocar las relaciones 'estéticas' entre los signos de un paisaje de lo visible le permite (re)escribir - poetizar, hacer poiesishorizontes de visibilidad desde la trascuenta, horizontes disensuales en los que la singularidad de lo múltiple excesivo, la singularidad proletaria, participa de un común (im)propio como hablante. Sí: desestabilizar la frontera en la que se decide el reparto político de la miseria en el mundo solo es posible "si aparece bajo la mano que escribe / la única cosa que parece / que puede ser llamada cosa de alguien" (Szymborska 2007, 74, énfasis mío), de alguno, del anónimo múltiple de la trascuenta que, como el significado indomable y huérfano de la letra, se reproduce sin ley. Alguno que, por qué no, puede abrir los ojos con el tacto de sus dedos, puede hacer mundos con sus manos - manos para ver. 


\section{El imperativo de la escritura}

El ahí del poema que se enuncia en los versos de Williams como el lugar en el que podría hallarse una manera de escapar de la lógica que hace que miles de hombres mueran miserablemente, el ahí de la escritura literaria, encuentra entonces su efectividad política en la medida en que revela, por así decirlo, que la letra no es ni ha sido nunca literalidad pura. El tejido de signos que configura lo 'real' —el reparto de lo sensible y el de lo común que es al tiempo su causa y su efecto) no es necesariamente nada debido a la circulación aleatoria e imprevisible de la escritura que, por consiguiente, no es sino el entrecruzamiento metafórico y siempre (re)configurable, (re)escribible, entre cuerpos y denominaciones en el que siempre puede abrirse un intervalo que se resiste a su clausura $o$ saturación: el pliegue de lo (im)propio, de las singularidad múltiple y excesiva, es decir de la trascuenta proletaria. La literatura puede acoger la miseria - $\mathrm{O}$, al menos, visibilizar la existencia inclasificable del outcast neutralizado como 'Otro miserable' - en virtud del poder que tiene la (im)propiedad de la escritura de reagenciar el reparto dado, esto es, de perforar el régimen de identificación de un logos policial y, así, ofrecer el intervalo en el que una(s) subjetividad(es) nueva(s), heterónomas y heterológicas, puede nacer. Unas subjetividades que, si bien la literatura misma no puede predecir o asegurar, pueden encontrar en el intervalo (im)propio de la escritura literaria el topos para enunciar su identidad múltiple singular: la identidad de un cuasi-cuerpo (literario, pero por ello mismo potencialmente político), la identidad de una voz/cuerpo que grita en su desincorporación.

La dislocación de los cortes que dan forma a la temida silueta del miserable, la dislocación que introduce el disenso en el cuerpo común y consensual que encuentra en dicha silueta su reflejo en negativo, es entonces la de la metáfora como posibilidad de subjetivación, aunque no ya inmediatamente como subjetivación. Como advierte Rancière, "las vías de la subjetivación política no son las de identificación imaginaria, sino aquellas de las desincorporación literaria" $(2009,51)$ o, diríamos, las de la literariedad que se abre en la metáfora hasta su explosión. El ahí del poema es el ahí del otro (im)propio cuyo cuasi-cuerpo literario hace 
explotar la universalidad del Otro de la ontología salvaje en la que se enclava la comunidad del consenso policial. En suma, el ahí del que nos habla Williams, el quiebre de la escritura como metáfora, es el operador de toda heterología, esto es, de la lógica de otro múltiple y excesivo - del proletario- en la que puede darse la subjetivación política (cf. Rancière 2006, 23). Bien sabemos que en un mundo sin metáforas, es decir un mundo sin poesía, no hay lugar para el disenso.

Si la subjetivación política sólo puede aflorar en intervalo (im) propio de la metáfora, el entre en el que pueden reagenciarse las asignaciones entre sujetos y predicados, el lenguaje en la que se (res)escribe el reparto de lo sensible como reparto de lo común y viceversa ha de ser un lenguaje, por decir lo menos, bilingüe. El proceso de la desidentificación como desincorporación literaria supone, sin duda, que los trazos del lenguaje admiten siempre su reconfiguración metafórica en más de una lengua escrita; de lo contrario, todo reparto sería siempre el mismo reparto o, por así decirlo, el horizonte saturado de una mismidad absoluta, de una escritura literal. Pareciera que, como nos confiesa el narrador argelino de la novela Amor bilingüe de Abdelkebir Khatibi ${ }^{7}$, el único imperativo de la escritura fuera ese, que la metáfora es siempre una traducción contingente y por tanto (im)propia entre los términos que en ella se tejen y que, en ese orden de ideas, en el corazón de todo lenguaje se mueve la asimetría o el desdoblamiento de lo bilingüe: "Esta idea se impone mientras la escribo: ¡todo lenguaje debe ser bilingüe!... La asimetría entre el cuerpo y el lenguaje, entre el discurso y la escritura" (1999, 5, trad. mía). Esta asimetría de lo bilingüe, que se

Pese a ser un dato biográfico que no pretende inscribir el sentido de su obra en una hermenéutica de la sospecha que, en última instancia, reproduciría un paradigma representativo o una lectura policial, es pertinente mencionar que el discurso literario de Khatibi se ubica en una frontera no-asignable: la del argelino poscolonial, francófono no francés. La reflexión sobre la traducción y el bi(pluri)lingüísmo que atraviesa su escritura está iluminada, como puede notarse en el carácter híbrido -o tránsfuga, diríamos con Rancière- de sus voces narrativas, por la conciencia del intervalo de enunciación en la que se ubica. Intervalo político-literario en la medida en que, como hemos observado en estas notas, hace visible una falla lógica en el sistema consensual que vincula una lengua a una esencia nacional, falla en la que el reparto de la ciudadanía se desvirtúa con la aparición de lo que podríamos llamar 'cuasi-cuerpos posnacionales': existencias plurilingües que (des)habitan el pliegue en el que acontece la traducción como (no-)lugar de lo propio impropio, de lo múltiple singular. 
anuncia desde nuestra relación de extrañamiento e (im)propiedad con la lengua madre (cf. Rancière 2006, 55), descubre que el proceso en el que "una subjetivación es una predicación impropia" (Rancière 2011b, 159) puede entenderse como el de una traducción (im)propia entre sujetos y predicados que en el orden policial son incompatibles ${ }^{8}$. Es en estos procesos de subjetivación como traducción en los que se forjan "comunidades aleatorias que contribuyen a la formación de colectivos de enunciación que vuelven a poner en cuestión la distribución de roles" (Rancière 2009, 51), colectivos de sujetos políticos que son, ante todo, sujetos bi(pluri)-lingües: sujetos cuya única propiedad común es su capacidad excesiva de (res)escribir el reparto dado en más de una lengua, es decir de traducir (im)propiamente modos de decir, hablar y ser y así poner de manifiesto que el lenguaje de lo común, no es ni ha sido nunca literal. De ahí que un colectivo político no sea un cuerpo comunitario; antes bien, es la fórmula de "una comunidad igualitaria, [...] una comunidad que sólo conoce singulares que se sostienen en la posibilidad infinita del uno-de-más" (Rancière 2006, 58) o, en última instancia, la posibilidad infinita de la traducción en la que todo múltiple singular puede hablar.

A la luz de las líneas de Khatibi, podemos concluir que el poder que la literatura tiene para acoger - en el sentido de hablar con ella, de abrirse a su existencia suspensiva- la miseria del mundo, consiste, en breve, en la fuerza de este imperativo heterológico del bi(pluri)lingüísmo que atraviesa a toda escritura: el imperativo de la letra escrita como metáfora insaturable, del ahí del poema en el que puede emerger una figura de identidad (im)propia del proletario en dos niveles. Primero, y como hemos

8 Pienso aquí también en las reflexiones de Rancière en El maestro ignorante (1987) a las que no alcanzo referirme, pero que sin duda serían muy iluminadoras, sobre el pensamiento de Joseph Jacotot y las operaciones de traducción impropia con las que se moviliza el proceso de la emancipación intelectual. La dislocación de la frontera entre logos y phoné que hemos observado como uno de los modos en los que la letra escrita hace visible la existencia suspendida del miserable como proletario están íntimamente ligadas con la desarticulación de la oposición entre el sabio y el ignorante, entre la razón y la voluntad y entre el pensamiento y la acción con la que se confirma lo que Jacotot llama 'la igualdad de las inteligencias' —igualdad que estaría, hasta cierto punto pendiente por determinar, enlazada con la igualdad de los hablantes que se abre en el intervalo literario como intervalo político. 
visto arriba, el carácter proliferante y no-asignable de la letra escrita, es decir su resistencia a la literalidad enmudecedora a la que quisiera someterla un logos regulador, abre el intervalo literario en el que puede tener lugar un proceso de subjetivación política o, lo que es lo mismo, de formación de una comunidad aleatoria de sujetos bi(pluri)lingües cuya excedencia traduce prácticas de órdenes sociales que no coinciden con el reparto de propiedades dado. Segundo, en la medida en que la literatura abre escenarios en los que puede escenificarse el daño que comparten los miserables, los fuera-de-cuenta que en la cuenta dada se someten a la ontología marginalizadora del no-poder-ser, la experiencia del exilio o del (in)habitar a la que nos exponemos cuando escribimos singularmente - y, habría que añadir, cuando leemos, cuando traducimos- nos ubica en una posición de (im)propiedad democrática, allí en donde podemos hablar como hablantes o emisores iguales con la multiplicidad singular de aquello que Rancière llamará démos, la «parte de los sin parte», el "suplemento respecto a todo recuento de las partes de una comunidad" (2011b, 164) que horada el consenso en el que esta se funda.

La potencia política de la literatura reside, pues, en que el gobierno que rige el reino de los cuasi-cuerpos que en ella se (re)producen sin ley reguladora, la ley que (des)ordena, que ordena en su polémica relación con todo orden, el horizonte heterotópico en el que la unicidad literal del logos se disemina en una infinidad imprevisible de lenguas/subjetividades en traducción, es "el gobierno de los que no tienen nada en común sino la ausencia de tales propiedades" (Rancière 2011b, 163). Una infinidad que no se proyecta hacia una utopía de igualdad sin polémica, que no se gravita en torno al no-lugar de un vacío de sentido infinitamente diseminado, sino que, muy por contrario, es políticamente significativa en la medida en que construye instancias de reclamo y litigio interviniendo en, y sirviéndose de, la lógica policial del logos que combate. Sí: la literatura es democrática en tanto que "la democracia de la escritura es el régimen de la letra en libertad [...], de una relación nueva entre el acto de la palabra, el mundo que éste configura y las capacidades de quienes lo pueblan" (Rancière 2011a, 29), de quienes habitan el intersticio en el que acontece esta configuración y reclaman para sí mismos, aquí y ahora, en este mundo y no en otro, su capacidad de enunciarla. 
Digámoslo sin miedo: en y desde la letra escrita, en y desde su cuasicuerpo desbordante, es posible sobreimprimir - reescribir, releer, traducir - la trascuenta proletaria sobre el mundo en el que la miseria es sólo miseria; en y desde el intervalo literario como intervalo potencialmente político, el miserable puede ser él mismo más allá de sí mismo en el horizonte (im)propio - pero jamás utópico- de la emancipación. Nadie está obligado, como escribe Rancière, a acoger toda la miseria del mundo, pero todos - todos en tanto cualquiera - podemos "al menos aprender a hablar, a hablar con ella, a nacer con ella en la singularidad del decir que inventa nombres, singularidades, multiplicidades nuevas" $(2006,57)$; aprender a nacer en y con la experiencia de desapropiación en la que nos sumerge la escritura literaria y, con ella y ya siempre más allá de ella, todas y cada una de las escrituras que (re)escriben el mundo en su múltiple singularidad.

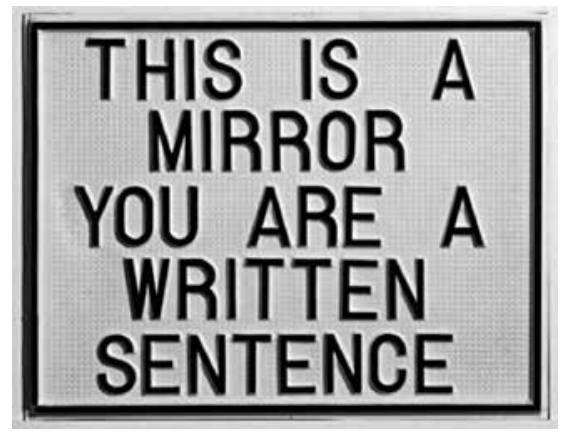

\section{Coda}

Esta imagen-texto del artista uruguayo Luis Camnitzer se escribe a sí misma como un espejo en el que el reflejo de la mirada que en él se posa es una oración desprovista de un emisor dado - el único presente es aquel que lee, que se lee en el enunciado negro: un aquel que es un cualquiera. El reflejo no es una imagen o un retrato identificable: es una oración escrita (You are a written sentence) que nos habla de un usted que no es nadie identificable. El reflejo es un pronombre que se reitera, en una suerte de tautología que recalca su carácter no-esencial, en un predicado que no predica nada en concreto sino que, al poner de manifiesto que el sujeto gramatical es un pronombre libre de predicados necesarios, anuncia que 
las posibilidades de su predicación son incontables, múltiples y excesivas. $\mathrm{Al}$ (no) ubicarse en un intervalo similar al de esta imagen-texto, al de esta interfase visual/escrita -imagen y/o texto que en sí misma desborda la frontera entre lo que es imagen y lo que es texto, entre un régimen de lo visible y uno de lo decible que no deben tocarse para conservar su propiedad-, el yo que nos mira/escribe de vuelta en este espejo escrito, en esta escritura espectral, es un cuasi-cuerpo que se forja en el mutismo de unas letras cuyo significado no está sujeto a la voluntad de un logos regulador, esto es, a la autonomía de una voz conveniente. El material metálico en el que leemos este texto repujado emula las convenciones visuales características los letreros y las señales que ordenan el espacio urbano trazando las líneas de unos comportamientos propios, adecuados o, diríamos, policialmente repartidos; sin embargo, aquí estas convenciones se dislocan dado que este entre que en la obra se abre (entre el sujeto y el predicado, entre lo visible y lo decible, entre la imagen muda y el texto que habla) es el no-lugar de un sensorium nuevo. La advertencia del ahí en el que se ubica nuestro reflejo frente a este espejo opaco es la de un imperativo heterológico, el imperativo de una propiedad impropia que (des)ordena nuestro mundo: la letra escrita "testimonia de la diferencia de cada uno consigo mismo" (Rancière 2006, 58) y, al hacerlo, permite que quien no puede pararse frente a la obra, quien muere miserablemente en las noticias, también hable allí - también nos mire de vuelta en nuestra mirada que, así, sólo es nuestra en tanto que no nos pertenece.

\section{Bibliografía}

Camnitzer, Luis (Artista plástico). 1966. THIS IS A MIRROR. YOU ARE A WRITTEN SENTENCE [obra de arte]. Recuperado el 28 de septiembre de 2013 de: http://www.nytimes.com/imagepages/2011/02/17/17 camnitzer-web1.html

Hrabal, Bohumil. 2009. Una soledad demasiado ruidosa. Traducido por Monika Zgustová. Barcelona: Destino.

Khatibi, Abdelkebir. 1990. Love in Two Languages (Amour bilingue). Traducido por Richard Howard. Minneapolis: University of Minesota Press. 
Rancière, Jacques. 2006. Política, policía, democracia. Traducido por María Emilia Tijoux. Santiago de Chile: LOM Ediciones.

Rancière, Jacques. 2009. El reparto de lo sensible: estética y política. Traducido por Cristóbal Durán et al. Santiago de Chile: LOM Ediciones.

Rancière, Jacques. 2011a. Política de la literatura. Política de la literatura. Traducido por Marcelo G. Burello et al. Buenos Aires: Libros del Zorzal. 15-54.

Rancière, Jacques. 2011b. El tiempo de la igualdad. Traducido por Javier Bassas. Barcelona: Herder.

Szymborska, Wislawa. 2007. Dos puntos. Traducido por Gerardo Beltrán. Tarragona: Igitur.

Vallejo, César. 2008. Quiero escribir, pero me sale espuma (antología). Bogotá: Universidad Externado de Colombia.

Williams, William Carlos. 1994. Asphodel, That Greeny Flower and Other Love Poems. Editado por Herbert Leibowitz. New York: New Directions Books. 